\title{
Emergency and disaster preparedness for chronically ill patients: a review of recommendations
}

\author{
This article was published in the following Dove Press journal: \\ Open Access Emergency Medicine \\ 8 December 2014 \\ Number of times this article has been viewed
}

\section{Jun Tomio'}

Hajime Sato ${ }^{2}$

'Department of Public Health, Graduate School of Medicine, The University of Tokyo, Tokyo, Japan; ${ }^{2}$ Department of Health Policy and Technology Assessment, National Institute of Public Health, Wako, Japan
Correspondence: Hajime Sato Department of Health Policy and Technology Assessment, National Institute of Public Health, 2-3-6 Minami, Wako, Saitama 35I-0197, Japan

Tel +8I 484586223

Fax +8I 484693875

Email hsato-tky@umin.ac.jp

\begin{abstract}
Recent disasters, especially those in developed countries, have highlighted the importance of disaster preparedness measures for chronic diseases. A number of surviving patients experienced the exacerbation of a chronic illness, such as hypertension, diabetes, cancer, and chronic respiratory diseases, due to disaster-related stress, interruption of care, or both; for some patients, these exacerbations resulted in death. Here, we review reports from recent disasters in developed countries and summarize the recommendations for disaster preparedness of chronically ill patients. A considerable number of recommendations based on the lessons learned from recent disasters have been developed, and they provide practical and essential steps to prevent treatment interruption during and after a disaster. To improve preparedness efforts, we suggest that health care providers should be aware of the following three suggestions: 1) recommendations should be evidence-based;2) recommendations should contain consistent messages; and 3) recommendations should be feasible.
\end{abstract}

Keywords: disaster, chronic illness, preparedness

\section{Introduction}

Recent disasters, especially those in developed countries, have highlighted the importance of preparedness measures for chronic diseases. ${ }^{1-3}$ After Hurricane Katrina, $58 \%$ of the visits to emergency treatment facilities in New Orleans were due to illness, and $24 \%$ of these visits were related to chronic diseases and their associated conditions. ${ }^{3}$ Furthermore, more than $70 \%$ of the Hurricane Katrina survivors had at least one chronic condition. ${ }^{4}$ In the affected area of the Great East Japan Earthquake (GEJE), a number of survivors experienced exacerbation of and death from chronic illnesses, including hypertension, diabetes, cancers, and chronic respiratory diseases, because of the direct stress of the disaster, the interruption of care, or both. ${ }^{5-10}$ In this context, disaster medicine and preparedness should be based on a more comprehensive approach rather than on the traditional, injuryoriented approach. ${ }^{2}$

Because of the rapidly aging population and progress in medical care, the number of patients with chronic diseases is increasing; therefore, health care providers need to prepare for future disasters to ensure the continuity of care for these patients. ${ }^{11-13}$ Because of this, health care providers and related organizations have developed guidelines for the preparedness and treatment of chronically ill patients. ${ }^{13-16}$ Here, we review evidence from recent disasters and summarize the recommendations for the disaster preparedness of and the treatment of chronically ill patients. 


\section{Methods}

Because the management of patients with chronic diseases may differ on the basis of general health and the financial status of the affected country, we focused only on reports and guidelines from developed countries. The search was conducted in PubMed for academic articles by using the medical subject headings "disasters" and "chronic diseases" as the search terms. We limited the search to those published from January 1, 2001-June 30, 2014 to collect findings with similar background characteristics, including population aging, treatment standards, and social infrastructure, that can influence the impact of disaster on chronic illnesses. From the resulting 186 articles, we selected those articles that were written in English or Japanese and that reported on natural disasters and terrorism events in developed countries. We also reviewed the reference lists of the selected articles, regardless of the publication year. In addition, we searched Google with the following search terms: 1) "disaster*"; 2) "chronic", "disease*"; and 3) "guidelines" (*indicates wildcard). We limited the search to English pages and to those updated between January 2001 and June 2014 . We obtained 252 pages, including portal sites, academic articles, newsletters, newspaper articles, guidelines, reports, presentation files, and proceedings. From these, we retrieved the relevant guidelines published by governmental organizations, nongovernmental organizations, and academic societies.

Although the term "chronic illness" includes various types of conditions, we tried to provide the overview of the recommendations rather than to comprehensively cover all of the recommendations for every disease. Hence, our primary focus was placed on major illnesses, including four noncommunicable diseases that the World Health Organization has listed - namely, cancer, cardiovascular disease, chronic respiratory diseases, and diabetes, ${ }^{17}$ as well as chronic kidney diseases requiring special preparedness for dialysis. Thus, we included all of the articles that described either chronic illnesses in general or at least one of the previously mentioned five illnesses, whereas we excluded the articles that provided disease-specific details of other illnesses or chronic conditions.

One of the authors, Jun Tomio, searched and reviewed the articles, and both of the authors (Jun Tomio and Hajime Sato) summarized the findings. The recommendations were summarized specifically for each major illness and for each type of stakeholder. They also included additional findings applicable to chronic illnesses in general.

\section{Results \\ Documented issues for patients with chronic diseases}

For chronically ill patients, interruptions in medication regimens and needed medical technologies can exacerbate underlying conditions and increase the risk of morbidity or mortality. ${ }^{2}$ A study of Hurricane Katrina showed that the evacuees with chronic diseases who required medications were nearly twice as likely to present with acute symptoms on arrival to shelters; of those evacuees, individuals with comorbidities were also three times more likely to be acutely ill on arrival than those with no other conditions. ${ }^{18}$ Interruption of routine treatments and subsequent exacerbations of blood pressure, blood glucose control, or both were also common among the survivors of GEJE. ${ }^{5,8,19-22}$

In addition to the interruption of treatment, conditions such as stress, the lack of food or water, extreme temperatures, and exposure to infection can contribute to the rapid worsening of a chronic illness that was well controlled before the event. ${ }^{2}$ In some studies, individuals with chronic conditions are more likely than those without chronic conditions to exhibit negative psychological consequences of disasters, ${ }^{23}$ although there are conflicting findings regarding this effect. ${ }^{24}$

\section{Recommendations for chronically ill patients}

Recommendations and guidelines have been provided by researchers, academic societies, and various organizations for disaster preparedness not only for chronically ill patients, but also for health care providers and policymakers who are involved in patient treatment. ${ }^{13-16}$ We summarized the disease-specific recommendations for patients and for health care providers and policymakers (Table 1). In addition, we also provided a summary of general recommendations that can be commonly applicable to different types of diseases.

\section{Disease-specific recommendations}

\section{Cancer}

Cancer is one of the leading causes of death in developed countries, and administration of oncology care has shifted primarily from hospitals to outpatient departments. ${ }^{25}$ Therefore, an increasing number of cancer patients are either in communities in the affected areas of disasters or in shelters in those areas. Although the direct effects of disasters on cancer patients have not been reported, cancer patients, especially those in active treatment, can have weakened immune systems and may be at higher risk for infections, bleeding, 


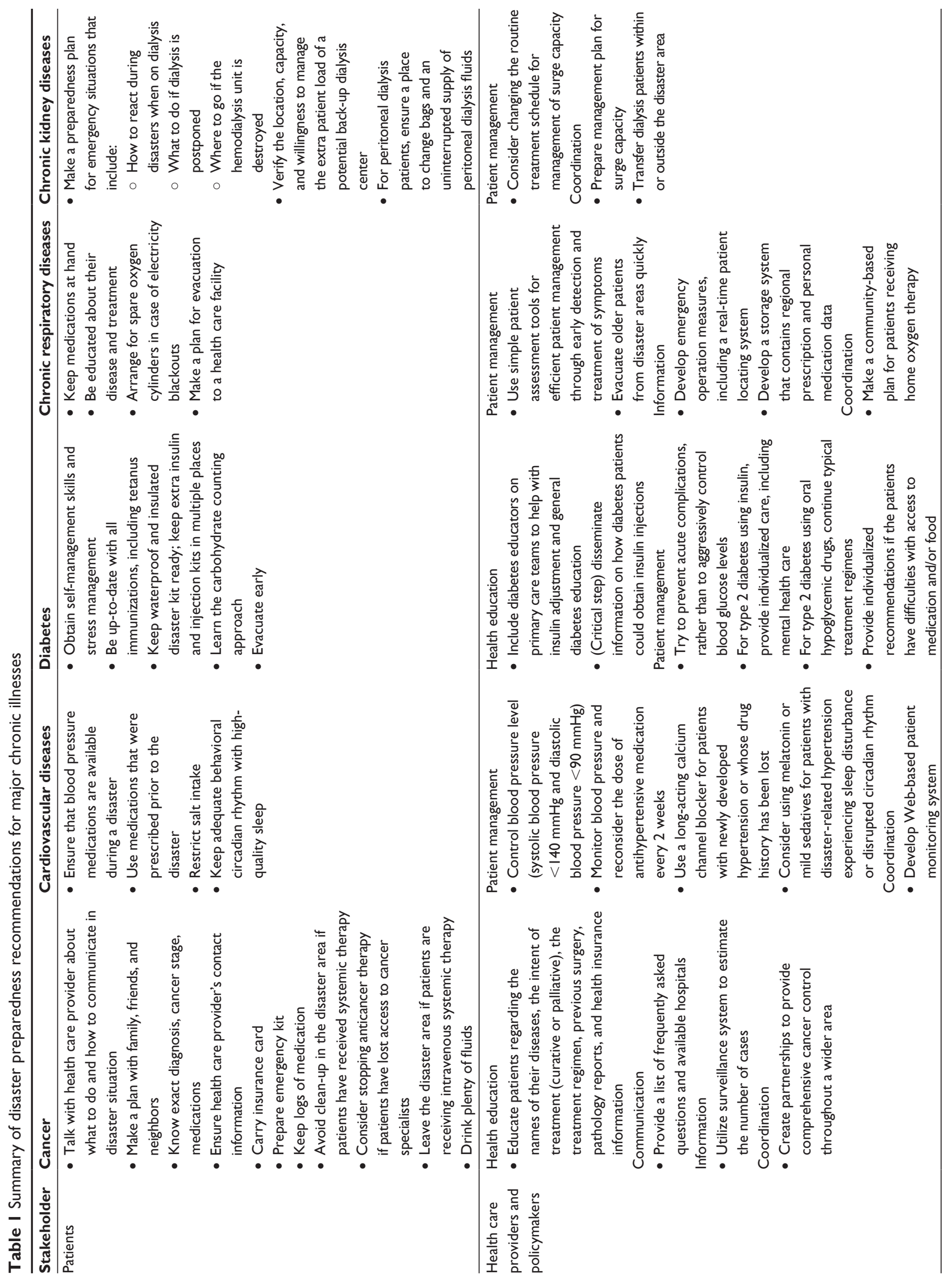


fatigue, and injury. ${ }^{15}$ In addition, disrupted treatment can affect treatment outcomes. ${ }^{26}$ According to a survey of cancer patients who were undergoing chemotherapy after the GEJE in $2011,62 \%$ of the patients experienced interruptions in treatment, and only $40 \%$ could complete their regimens per the original treatment plan. ${ }^{25}$

\section{Recommendations for patients}

The National Cancer Institute provides seven tips for cancer patients to prepare themselves for disasters: ${ }^{15}$ 1) patients should talk with their health care providers about what to do and how they will stay in contact in the event of a disaster; 2) patients should make a plan with their family, friends, and neighbors; 3 ) each patient should know his or her exact diagnosis, cancer stage, medications, and treatment cycle; 4) if a patient is on a clinical trial, that patient should know its details; 5) each patient should make sure to have his or her health care provider's contact information available, even in emergencies; 6) if patients have insurance, they should make sure to carry their insurance cards; and 7) each patient should make a kit with the items that he or she may need. ${ }^{15}$ Although the tips are written for cancer patients, they are comprehensive and generally in line with the recommendations for other chronic conditions.

In addition, after their experience with the recent earthquake in Japan, Imamura and Ueno summarized the following recommendations for cancer patients during disasters: ${ }^{27}$ 1) patients should keep logs of their medications, including names and doses; 2) if patients have received systemic therapy that could possibly impair their immune systems, they should avoid clean-up in the disaster area; 3 ) if patients are taking anticancer therapy, they may want to stop taking these drugs if they have lost access to cancer specialists; 4 ) if patients are receiving intravenous systemic therapy, they should leave the disaster area; 5) patients should drink plenty of fluids to prevent dehydration; and 6) patients should prevent thrombosis.

\section{Recommendations for health care providers and policymakers}

Because cancer treatments are often complex, individualized, and multidisciplinary, health care providers should make a special effort to educate each patient regarding the name of his or her disease, the intent of his or her treatment (curative or palliative), his or her treatment regimen, his or her previous surgery, his or her pathology reports, and his or her health insurance information. ${ }^{26-30}$ Education regarding disaster preparedness specifically can be accomplished by providing a list of frequently asked questions and available hospitals. $^{27}$

An important preparedness activity is creating partnerships to provide comprehensive cancer control throughout a wider area. ${ }^{30}$ After Hurricane Katrina, Louisiana's Comprehensive Cancer Control Program remained functional because of a decentralized management structure and strong partnerships. ${ }^{30}$ Hurricane Katrina directly affected only one of the nine regions in Louisiana, and regional coalitions continued local comprehensive cancer control activities in the unaffected eight regions; this process resulted in minimal disruption to comprehensive cancer control activities in most of the state. ${ }^{30}$ The utilization of a surveillance system to estimate the number of cases in the affected area can also be effective because cancer registries are common in developed countries. ${ }^{31}$

\section{Cardiovascular diseases}

Cardiovascular diseases, including hypertension and heart disease, are the most prevalent chronic diseases in the majority of the world. ${ }^{17}$ As a result, the effects of disasters have been well documented. ${ }^{16,32-35}$ These effects include increases in fatal and nonfatal cardiovascular events. Also included is the exacerbation of problems with blood pressure control; ${ }^{16,32-36}$ increases in systolic blood pressure of 5-25 mmHg have been reported. ${ }^{16}$ Disasters can trigger cardiovascular events predominantly through sympathetic nervous system activation and potentiation of acute risk factors, including disaster-related hypertension, increased heart rate, endothelial cell dysfunction, increased blood viscosity, and platelet and hemostatic activation.

In most patients, the increases in clinic- and self-measured blood pressure are transient, and blood pressure levels return to the predisaster baseline levels within 4 weeks. ${ }^{16}$ However, disaster-related increases in blood pressure are greater and sustained longer (several months) in those with salt sensitivity, like the elderly and patients with chronic kidney disease, obesity, or metabolic syndrome. ${ }^{16}$ Disrupted lifestyle rhythms and patterns, sleep difficulties, and disruption of normal dietary habits can also exacerbate blood pressure control, leading to unfavorable outcomes. ${ }^{8}$

\section{Recommendations for patients}

Patients with hypertension, in particular, should plan to have blood pressure medications available for a disaster and to use those that were prescribed prior to the disaster. ${ }^{8}$ Strict salt restriction and maintenance of adequate 
behavioral circadian rhythms with high-quality sleep are also recommended. ${ }^{16}$

\section{Recommendations for health care providers and policymakers}

It is recommended that blood pressure levels should be monitored and that the dose of antihypertensive medication should be reconsidered every 2 weeks during the disaster situation. ${ }^{8,16}$ Health care providers should be aware that persistent and intense antihypertensive treatment for subjects with high blood pressure at the time of a disaster could result in excessive blood pressure reduction because blood pressure could decrease at some point after the disaster. ${ }^{16}$ There are currently no data regarding target blood pressure levels for disaster-related hypertension, but a tentative recommendation indicates a systolic blood pressure $<140 \mathrm{mmHg}$ and a diastolic blood pressure $<90 \mathrm{mmHg} .{ }^{16}$

Regarding the use of antihypertensive agents, a long-acting calcium channel blocker is recommended, particularly for victims with newly developed disaster-related hypertension or whose drug history has been lost. This class of antihypertensive agent is effective and safe for all patients and has no major side effects. ${ }^{8}$ Depending on body fluid volume, the effectiveness of angiotensin receptor blockers markedly varies in lowering blood pressure, whereas renin-angiotensin system inhibitors carry the risk of even greater variability in lowering blood pressure. ${ }^{8}$ In patients with persistently elevated blood pressure with reninangiotensin system inhibitors, these drugs should be used in conjunction with a small dose of an appropriate diuretic. ${ }^{8}$ Evening administration of melatonin, a melatonin receptor agonist, or a mild sedative may be effective to lower blood pressure in patients with drug-resistant disaster-related hypertension who are experiencing sleep disturbances or disrupted circadian rhythms. ${ }^{16}$

In addition to traditional monitoring approaches, a patient monitoring system that uses Web-based technology was developed recently. ${ }^{37,38}$ The Disaster Cardiovascular Prevention score was developed as an assessment and prevention score system for disaster-related cardiovascular events to enable individualized care. ${ }^{8,37,39}$ After the GEJE, this scoring system was introduced as a network approach with an Internet-based blood pressure monitoring system in some areas, and anecdotal evidence indicates that it was effective. ${ }^{8}$ A remote monitoring system that uses implantable devices for patients with congestive heart failure was also found to effectively improve the detection time and therapy for patients in devastated areas with heart failure. ${ }^{38}$

\section{Diabetes}

The abrupt change in dietary intake or composition, a lack of diabetes medication, and emotional stress, such as stressrelated somatic symptoms, sleep disturbances or anxiety, and social dysfunction, can lead to significant disruption in glycemic control in patients with diabetes; therefore, patients might be put at risk of both severe hyperglycemia and hypoglycemia. ${ }^{14,40}$ In addition to poorer glycemic control, increases in cardiovascular risk from elevated blood pressure have been reported in past disasters. ${ }^{20,41}$ Among Hurricane Katrina victims, the rate of recovery to predisaster levels of clinical and biochemical parameters related to diabetes and its comorbidities varied..$^{42}$ Therefore, the management of patients with diabetes during and after a disaster should aim to prevent acute complications of diabetes, such as hyperosmolar states, severe hypoglycemia, and cardiovascular events, rather than to aggressively control blood glucose levels. ${ }^{14,41}$ In this regard, primary care disaster relief teams should include diabetes educators to help with insulin adjustment and general diabetes education. ${ }^{14}$

\section{Recommendations for patients}

By using the lessons learned from Hurricane Katrina, the American Diabetes Association (ADA) developed a comprehensive preparedness statement for health care providers as well as diabetes patients ${ }^{14}$ that included four points for diabetes patients: 1) patients should obtain good diabetes education that emphasizes self-management skills and stress management; 2) patients should be up-to-date with all immunizations, including tetanus; 3) patients should keep a waterproof and insulated disaster kit ready with a list of items to pack during an evacuation, such as glucose testing strips, medications, glucose tabs, a list of contacts for national organizations such as ADA (either their help lines or their internet addresses), photocopies of relevant medical information (particularly recent lab tests and procedures, if available), and up-to-date information regarding formulation and dosing for all oral medications and insulin; and 4) patients should evacuate early, if possible, and take with them the items that were previously listed. ${ }^{14}$ In addition to these general recommendations, the United States Food and Drug Administration provides some useful technical information regarding insulin storage and changing insulin products; this resource should be referenced when the patients or health care provider have difficulties using insulin in emergency situations. ${ }^{43}$ 


\section{Recommendations for health care providers}

\section{and policymakers}

Although the ADA statement encourages the teaching of self-management skills, ${ }^{14}$ Kishimoto and Noda ${ }^{6}$ emphasized the importance of educating patients as well as local medical staff who do not specialize in diabetes, as it is not easy for patients to adjust their medications without assistance.

For the management of patients with diabetes during and after a disaster, Kishimoto and Noda ${ }^{6,19}$ provided practical recommendations for different types of diabetes from their experience during the GEJE. As insulin injections are indispensable for the survival of patients with type 1 diabetes and some patients with type 2 or other types of diabetes, dissemination of information about how such patients could obtain insulin injections is critical. ${ }^{6}$ The discontinuation of insulin injections can lead to serious consequences in patients with type 1 diabetes; therefore, such patients should keep extra insulin and injection kits in multiple places, such as at home, at the office, and at school, in preparation for a sudden-onset disaster. ${ }^{6}$ For patients with type 2 diabetes who are using insulin, the pathophysiological conditions of the patients can be diverse and require individualized care, including mental health care. ${ }^{6}$

With oral hypoglycemic agent therapy for type 2 diabetes, the typical treatment regimens should be continued. ${ }^{6}$ However, individualized recommendations should be provided if the patients do not have access to their medications or are no longer able to consume a fixed amount of food. ${ }^{6}$ The discontinuation of glucosidase inhibitors, biguanides, and thiazolidinediones has a relatively low risk of rapid deterioration in diabetic control. However, interruption in sulfonylureas or glinides can cause a hypoglycemic attack if enough food is not consumed; therefore, the dosage should be adjusted accordingly. ${ }^{6}$ Incretin-related drugs, such as dipeptidyl peptidase-4 inhibitors, glucagon-like peptide-1 analogs, and glucagon-like peptide-1 receptor agonists, are associated with a low risk of hypoglycemia when they are used as a monotherapy, and a patient can take his or her usual dose as long as he or she has a meal. ${ }^{6}$

In addition to medical management, an appropriate diet is also important, ${ }^{44}$ and some experts recommend that patients with type 1 diabetes should learn the carbohydrate counting approach to become aware of the importance of the carbohydrate-to-insulin ratio. ${ }^{45}$

\section{Chronic respiratory diseases}

Chronic obstructive pulmonary disease (COPD) is among the most common chronic respiratory diseases, especially in the elderly. ${ }^{46}$ Several reports have documented exacerbations in COPD symptoms after disasters; this pattern is presumably caused by interruptions in medication schedules and by infections related to poor hygiene and to overcrowding in shelters. ${ }^{7,9,46,47}$ According to a report from a regional core hospital in the affected area of the GEJE, a significant number of COPD patients who had been receiving long-term oxygen therapy at home presented at the hospital after power failure or equipment damage caused the loss of their stable oxygen supplies. ${ }^{7}$ Although none of the patients presented with exacerbated symptoms, an increase in hospital admissions continued for up to 5 weeks after the disaster because of COPD exacerbations. ${ }^{7}$

Patients with asthma, another common chronic respiratory illness, can also experience deterioration in their condition after disasters; ${ }^{9,48,49}$ this deterioration can be minimized or prevented if patients are appropriately treated with inhaled corticosteroids. ${ }^{50}$ Adequate treatment and education can play an important role in the prevention of asthma exacerbation after severe disasters such as earthquakes. ${ }^{50}$

\section{Recommendations for patients}

Because long periods in shelters ( $>3$ weeks) can result in deterioration in activities of daily living status and hospitalization for respiratory diseases, some experts recommend that older patients should be evacuated from disaster areas as quickly as possible. ${ }^{46}$ Patients with chronic respiratory diseases should keep their medications at hand and be educated about their diseases and treatments. ${ }^{46,50}$ For patients undergoing oxygen therapy, it is recommended that they arrange for spare oxygen cylinders in case of electricity blackouts and that they plan for evacuation to a health care facility. ${ }^{51}$

\section{Recommendations for health care providers and policymakers}

In Japan, after the Great Hanshin Earthquake of 1995, medical personnel and home oxygen service providers established emergency operation measures for a disaster, ${ }^{51}$ including a real-time patient locating system that was developed by oxygen service providers and was effective during emergency evacuations in the aftermath of the GEJE. ${ }^{9}$ Community-based plans for patients receiving home oxygen therapy are also required. ${ }^{51}$

A stable supply of essential drugs, in addition to a psychological support system, can also be important to maintain disease control during disaster conditions ${ }^{50}$ by 
preventing treatment interruptions. This necessitates a storage system that contains regional prescription and personal medication data.

In most hospitals, it is difficult to conduct routine patient examinations because of infrastructure damage and a lack of staff; therefore, simple assessment tools, such as the Asthma Control Test, can contribute to efficient patient management through early detection of and treatment of symptoms. ${ }^{47}$

\section{Chronic kidney diseases}

Patients with chronic kidney disease, especially those with end-stage renal disease and those that depend on routine dialysis, are highly vulnerable in disaster situations. Patients with chronic kidney disease are reportedly more likely to experience elevated blood pressure and to be at a higher risk for cardiovascular diseases, presumably because disaster-related stress activates the sympathetic nervous system. ${ }^{10,22}$

\section{Recommendations for patients}

Because effective treatment depends on a number of factors, it is strongly recommended that patients make preparedness plans for emergency situations ${ }^{52}$ that include the following considerations: 1) how to react during disasters when on dialysis; 2) what to do if dialysis is postponed; and 3) where to go if the hemodialysis unit is destroyed. ${ }^{53,54}$ When a potential back-up dialysis center is identified, patients should verify the location, capacity, and willingness to manage the extra patient load..$^{54}$ In contrast to hemodialysis patients, peritoneal dialysis patients are less likely to experience issues in the continuity of treatment, but they should ensure a place to change bags and an uninterrupted supply of peritoneal dialysis fluids. ${ }^{55}$

\section{Recommendations for health care providers and policymakers}

The treatment and management of end-stage renal disease are highly dependent upon infrastructure and resources, such as water distribution systems, ground deliveries, access, light, heat, water delivery systems, transportation infrastructure, and the existence and function of dialysis centers with adequate supplies. Therefore, one of the primary roles of health care providers is the restoration of dialysis facilities and the transfer of dialysis patients within or outside the disaster area. ${ }^{56}$ The dialysis facilities should also be available for patients with injuries relating to being crushed under a heavy load, especially after a strong earthquake. Effective coordination of patient distribution and resource allocations by relevant organizations is essential. ${ }^{52,55} \mathrm{~A}$ management plan for surge capacity is also important. In the aftermath of the GEJE, a facility was forced to provide shorter periods of hemodialysis (by $0.5-1$ hour) for 1 month because of a shortage of resources, and no adverse effects were detected for the patients. ${ }^{57}$ This type of change in routine treatment can be a possible solution for the management of surge capacity after a disaster.

\section{General recommendations}

In addition to the disease-specific recommendations, previous researches provided common considerations for health care providers and policymakers to achieve continuity of care during a disaster. We summarized the findings according to the five topics provided by Arrieta et al: ${ }^{13} 1$ ) advance prescriptions; 2) patient knowledge of medications; 3) medical records; 4) medication and medical supplies; and 5) coordination of aid. Although these items do not cover all of the key issues in the care of chronic disease patients during disasters, most of the existing recommendations can be categorized into these five subgroups.

\section{Advance prescriptions}

Previous incidents have demonstrated that postdisaster continuity of care, especially continuation of daily medication for persons with chronic illnesses, is vital. ${ }^{12}$ Therefore, in the event of an imminent storm, health care providers or policymakers should relax public and private insurance stipulations on the periodicity of medication refills. ${ }^{13}$ Although health insurance systems vary among countries, a flexible prescription policy was implemented for the affected people in Japan after the earthquake in 2011 and was found to be effective..$^{50}$ It is also important for patients to reserve their essential medications, especially in case of sudden-onset disasters. Some guidelines provide suggested amounts of medication. However, the recommended amounts are inconsistent; ${ }^{58}$ they vary from doses for 3 days ${ }^{59}$ to doses for 1 month, ${ }^{12}$ and they depend on the medication type and volume, as well as on whether the prescription regulations are controlled at the country or state level ${ }^{58}$ However, it is probably safe to have a supply for 1-2 weeks after a large-scale disaster that severely affects the health care access and supply chain, such as Hurricane Katrina and the GEJE did. ${ }^{19,60,61}$ To be prepared for sudden-onset disasters like earthquakes and flash floods, it is also recommended to keep essential medications on hand at all times rather than to store them at home. ${ }^{19,62,63}$ In addition, it may be useful to keep supplies of medications in different places. ${ }^{19}$ 


\section{Patient knowledge of medications}

Written summaries of health and medication information should be provided to patients in paper or electronic format, and each patient should be educated regarding his or her diagnosis and specific treatment regimens. ${ }^{13}$ However, health care providers must take extra care when providing messages to vulnerable patients, including those with severe conditions and those with insufficient preparedness, as they require more intensive and individualized advice. ${ }^{19,27,58}$ Furthermore, to ensure that patients receive emergency preparedness knowledge for their chronic conditions as standard of care, it is necessary to mobilize educational materials to health care providers, including physicians and pharmacists. ${ }^{58}$

\section{Medical records}

Ensuring that health care personnel have access to prior medical records is important for continuing prior treatment regimens; ${ }^{4}$ therefore, the capacity to allow remote access of electronic medical records in community health centers needs to be established across institutional boundaries. ${ }^{13}$ Electronic personal health records managed by the patients, rather than by the health care provider, may also be a good option. ${ }^{64}$ If the medical records are not available because of severe infrastructure damage, as seen in the aftermath of the GEJE, health insurance claims data that contain diagnosis and prescription information can be alternatively used because they are usually stored in a remote place, although the volume and contents are limited. ${ }^{65}$

\section{Medication and medical supplies}

To achieve the effective and efficient distribution of medications and medical supplies, a centralized structure for the coordination of receipt and distribution of health care resources is recommended. ${ }^{13}$ However, at the same time, a decentralized structure is preferable to facilitate patient access to distribution sites. ${ }^{13}$ Establishing a network or partnership among health care institutions, pharmaceutical companies, and community-based aid organizations before the event can be effective to determine the required critical supplies and streamline postdisaster distribution. ${ }^{13,58}$

\section{Coordination of aid}

Policymakers should support a structure that facilitates the coordination of external aid with indigenous institutions to promote the long-term effects on the health of the community. ${ }^{13}$ Ko et $a^{58}$ suggested that partnerships should be established between preparedness organizations and chronic disease organizations, such as advocacy groups and providers, to address the needs of these populations for improved community resiliency and recovery. The National Standards for State and Local Planning provided by the Centers for Disease Control in the US also encourage these types of partnerships when building public health preparedness capabilities. ${ }^{58,66}$

In addition to these five issues, Mokdad et $\mathrm{al}^{2}$ suggested a preparedness approach based on an epidemiological needs assessment that utilizes the public health surveillance system. Such a surveillance tool should have at least three components: 1) the ability to establish a baseline of the size, the functional status, and the needs of the vulnerable populations in areas susceptible to predictable disasters; 2) the ability to assess the needs and levels of actual response during the disasters; and 3) the ability to monitor the long-term effects of the emergency. The Behavior Risk Factor Surveillance System in the US can provide useful baseline information about the numbers of people with chronic diseases and the treatment that they receive; this information can support health care providers to assess the needs of people with chronic diseases after disasters and while planning relief efforts. ${ }^{1}$ A surveillance system supported by the geographical information system can be more informative and can achieve efficient and timely relief activity. ${ }^{67}$ Monitoring pharmaceutical use among evacuees can be combined with traditional disease surveillance to help determine public health priorities after disasters. ${ }^{68}$

\section{Discussion}

A considerable number of recommendations for the disaster preparedness of chronically ill patients have been developed on the basis of the lessons learned from recent disasters. Each recommendation emphasizes the practical and essential message of preventing an interruption in treatment during and after a disaster. However, we would like to introduce three suggestions for the future improvement of disaster preparedness.

First, the recommendations need to be more evidencebased. Although some of the recommendations are based on epidemiological findings from past disasters, a large number are based on anecdotal evidence or expert opinions. Moreover, most of the recommendations have not been validated scientifically. It is, of course, very difficult or almost impossible to test the effects of disaster preparedness by using a sound epidemiological study design because of the unpredictable and sudden-onset nature of disasters, and some experts have suggested that the availability of recommendations should 
help organize the advance planning and the promotion of correct therapeutic approaches, even if the recommendations lack an evidence base. ${ }^{54}$ However, such recommendations should be validated by the best available methods and revised or updated accordingly. Events that happen more periodically, such as hurricanes and typhoons, could be viewed as opportunities for validation.

Second, the information provided in the recommendations should be made consistent, at least at the regional level, through a collaboration of relevant organizations including those for patient representatives. Inconsistent messages, such as the recommended extra medication doses and the timing of insulin injections, may cause some confusion for patients and health care providers.

Third, the recommendations should be feasible for the patients. Some recommendations, such as keeping extra medication doses, understanding the details of diagnosis and treatment, and seeking care outside the affected area, are theoretically effective, but may not be feasible for all patients. Chronically ill patients are generally vulnerable and more likely to be of lower socioeconomic status. Therefore, some recommendations may not be achievable for a specific subgroup of the patients. Disparities in preparedness status have been found in a variety of situations, presumably because of patient characteristics, including educational level, financial status, the presence of caregivers, and the awareness of disaster risk. ${ }^{61,69-74}$ Thus, effective and culturally relevant communications regarding health risks with disasters are crucial to improving preparedness levels, especially among these vulnerable populations. ${ }^{58,70}$ To provide more feasible preparedness recommendations, a balanced combination of patient and health care provider preparedness is required in the presence of collaboration efforts by governmental and nongovernmental organizations.

\section{Acknowledgments}

This study was supported by the Grant-in-Aid for Young Scientists (B) (24790497) and Grant-in-Aid for Scientific Research (24590827) from the Japan Society for the Promotion of Science.

\section{Disclosure}

The authors report no conflicts of interest in this work.

\section{References}

1. Ford ES, Mokdad AH, Link MW, et al. Chronic disease in health emergencies: in the eye of the hurricane. Prev Chronic Dis. 2006; 3(2):A46.
2. Mokdad AH, Mensah GA, Posner SF, Reed E, Simoes EJ, Engelgau MM; Chronic Diseases and Vulnerable Populations in Natural Disasters Working Group. When chronic conditions become acute: prevention and control of chronic diseases and adverse health outcomes during natural disasters. Prev Chronic Dis. 2005;2 Spec no:A04.

3. Sharma AJ, Weiss EC, Young SL, et al. Chronic disease and related conditions at emergency treatment facilities in the New Orleans area after Hurricane Katrina. Disaster Med Public Health Prep. 2008;2(1): 27-32.

4. Kessler RC; Hurricane Katrina Community Advisory Group. Hurricane Katrina's impact on the care of survivors with chronic medical conditions. J Gen Intern Med. 2007;22(9):1225-1230.

5. Aoki T, Fukumoto Y, Yasuda S, et al. The Great East Japan Earthquake disaster and cardiovascular diseases. Eur Heart J. 2012;33(22): 2796-2803.

6. Kishimoto M, Noda M. Diabetes care: after the Great East Japan Earthquake. J Diabetes Investig. 2013;4(1):97-102.

7. Kobayashi S, Hanagama M, Yamanda S, et al. Impact of a large-scale natural disaster on patients with chronic obstructive pulmonary disease: the aftermath of the 2011 Great East Japan Earthquake. Respir Investig. 2013;51(1):17-23.

8. Nishizawa M, Hoshide S, Shimpo M, Kario K. Disaster hypertension: experience from the great East Japan earthquake of 2011. Curr Hypertens Rep. 2012;14(5):375-381.

9. Ohkouchi S, Shibuya R, Yanai M, Kikuchi Y, Ichinose M, Nukiwa T. Deterioration in regional health status after the acute phase of a great disaster: respiratory physicians' experiences of the Great East Japan Earthquake. Respir Investig. 2013;51(2):50-55.

10. Tani Y, Nakayama M, Tanaka K, et al. Blood pressure elevation in hemodialysis patients after the Great East Japan Earthquake. Hypertens Res. 2014;37(2):139-144.

11. Aldrich N, Benson WF. Disaster preparedness and the chronic disease needs of vulnerable older adults. Prev Chronic Dis. 2008;5(1):A27.

12. Arrieta MI, Foreman RD, Crook ED, Icenogle ML. Insuring continuity of care for chronic disease patients after a disaster: key preparedness elements. Am J Med Sci. 2008;336(2):128-133.

13. Arrieta MI, Foreman RD, Crook ED, Icenogle ML. Providing continuity of care for chronic diseases in the aftermath of Katrina: from field experience to policy recommendations. Disaster Med Public Health Prep. 2009;3(3):174-182.

14. Disaster Response Task Force. American Diabetes Association statement on emergency and disaster preparedness: a report of the Disaster Response Task Force. Diabetes Care. 2007;30(9):2395-2398.

15. National Cancer Institute at the National Institutes of Health [webpage on the Internet]. Help for cancer patients and researchers affected by catastrophic events. Bethesda, MD: National Cancer Institute; 2011. Available from: http://www.cancer.gov/aboutnci/emergency/disasters. Accessed August 1, 2014.

16. Kario K. Disaster hypertension - its characteristics, mechanism, and management - . Circ J. 2012;76(3):553-562.

17. World Health Organization [webpage on the Internet]. Noncommunicable diseases. Geneva, Switzerland: World Health Organization; 2013. Available from: http://www.who.int/mediacentre/factsheets/fs355/en/. Accessed August 1, 2014.

18. Greenough PG, Lappi MD, Hsu EB, et al. Burden of disease and health status among Hurricane Katrina-displaced persons in shelters: a population-based cluster sample. Ann Emerg Med. 2008;51(4): 426-432.

19. Kishimoto M, Noda M. The Great East Japan Earthquake: experiences and suggestions for survivors with diabetes (perspective). PLoS Curr. 2012;4:e4facf9d99b997.

20. Ogawa S, Ishiki M, Nako K, et al. Effects of the Great East Japan Earthquake and huge tsunami on glycaemic control and blood pressure in patients with diabetes mellitus. BMJ Open. 2012;2(2):e000830.

21. Tanaka K, Nakayama M, Tani Y, et al. The Great East Japan Earthquake: blood pressure control in patients with chronic kidney disease. Am J Hypertens. 2012;25(9):951-954. 
22. Watanabe K, Tani Y, Tanaka K, et al. Acute changes in home blood pressure after the Great East Japan Earthquake among patients with chronic kidney disease in Fukushima City. Clin Exp Nephrol. 2013;17(5):718-724.

23. Rath B, Donato J, Duggan A, et al. Adverse health outcomes after Hurricane Katrina among children and adolescents with chronic conditions. J Health Care Poor Underserved. 2007;18(2):405-417.

24. van den Berg B, van der Velden PG, Joris Yzermans C, Stellato RK, Grievink L. Health-related quality of life and mental health problems after a disaster: are chronically ill survivors more vulnerable to health problems? Qual Life Res. 2006;15(10):1571-1576.

25. Akiyama S, Seya Y, Murayama M, et al. [A multicenter trial of regional medical cooperation for cancer chemotherapy after the Great East Japan Earthquake]. Gan To Kagaku Ryoho. 2013;40(3):343-348. Japanese.

26. Ullman K. Cancer care during natural disasters. J Natl Cancer Inst. 2011;103(24):1819-1820.

27. Imamura CK, Ueno NT. Health services: How can we address cancer care after a natural disaster? Nat Revi Clin Oncol. 2011;8(7):387-388.

28. Bosley C. How did you continue to provide cancer care for patients after a natural disaster? ONS Connect. 2012;27(5):15.

29. Dolan TB. Cancer care when disaster strikes. ONS Connect. 2012;27(5): $10-14$.

30. Williams D, Kaufman R, Hayden J, Robinson M, Tai E. Comprehensive cancer control in the eye of Hurricane Katrina. Prev Chronic Dis. 2009;6(4):A139.

31. Joseph DA, Wingo PA, King JB, et al. Use of state cancer surveillance data to estimate the cancer burden in disaster-affected areas - Hurricane Katrina, 2005. Prehosp Disaster Med. 2007;22(4):282-290.

32. Jordan HT, Stellman SD, Morabia A, et al. Cardiovascular disease hospitalizations in relation to exposure to the September 11, 2001 World Trade Center disaster and posttraumatic stress disorder. $J$ Am Heart Assoc. 2013;2(5):e000431.

33. Kario K, Matsuo T, Shimada K, Pickering TG. Factors associated with the occurrence and magnitude of earthquake-induced increases in blood pressure. Am J Med. 2001;111(5):379-384.

34. Kario K, McEwen BS, Pickering TG. Disasters and the heart: a review of the effects of earthquake-induced stress on cardiovascular disease. Hypertens Res. 2003;26(5):355-367.

35. Krousel-Wood MA, Islam T, Muntner P, et al. Medication adherence in older clinic patients with hypertension after Hurricane Katrina: implications for clinical practice and disaster management. $\mathrm{Am} \mathrm{J} \mathrm{Med}$ Sci. 2008;336(2):99-104.

36. Steinberg JS, Arshad A, Kowalski M, et al. Increased incidence of lifethreatening ventricular arrhythmias in implantable defibrillator patients after the World Trade Center attack. J Am Coll Cardiol. 2004;44(6): 1261-1264.

37. Kario K, Nishizawa M, Hoshide S, et al. Development of a disaster cardiovascular prevention network. Lancet. 2011;378(9797):1125-1127.

38. Suzuki H, Yamada S, Kamiyama Y, Takeishi Y. Efficacy of intrathoracic impedance and remote monitoring in patients with an implantable device after the 2011 Great East Japan Earthquake. Int Heart J. 2014;55(1): 53-57.

39. Kario K. Disaster hypertension - its characteristics, mechanism, and management. Circ J. 2012;76(3):553-562.

40. Fujihara K, Saito A, Heianza Y, et al. Impact of psychological stress caused by the Great East Japan Earthquake on glycemic control in patients with diabetes. Exp Clin Endocrinol Diabetes. 2012;120(9): 560-563.

41. Kamoi K, Tanaka M, Ikarashi T, Miyakoshi M. Effect of the 2004 Mid-Niigata Prefecture earthquake on home blood pressure measurement in the morning in type 2 diabetic patients. Clin Exp Hypertens. 2006;28(8): 719-729.

42. Thethi TK, Yau CL, Shi L, et al. Time to recovery in diabetes and comorbidities following Hurricane Katrina. Disaster Med Public Health Prep. 2010;4 Suppl 1:S33-S38.
43. US Food and Drug Administration [webpage on the Internet]. Information regarding insulin storage and switching between products in an emergency. Silver Spring, MD: US Food and Drug Administration; 2013. Available from: http:/www.fda.gov/Drugs/EmergencyPreparedness/ ucm085213.htm. Accessed. August 1, 2014.

44. Cefalu WT, Smith SR, Blonde L, Fonseca V. The Hurricane Katrina aftermath and its impact on diabetes care: observations from "ground zero": lessons in disaster preparedness of people with diabetes. Diabetes Care. 2006;29(1):158-160.

45. Sengül A, Ozer E, Salman S, et al. Lessons learnt from influences of the Marmara earthquake on glycemic control and quality of life in people with type 1 diabetes. Endocr J. 2004;51(4):407-414.

46. Yamanda S, Hanagama M, Kobayashi S, et al. The impact of the 2011 Great East Japan Earthquake on hospitalisation for respiratory disease in a rapidly aging society: a retrospective descriptive and cross-sectional study at the disaster base hospital in Ishinomaki. BMJ Open. 2013;3(1). pii: e000865.

47. Ishiura Y, Fujimura M, Yamamoto H, et al. Asthma exacerbations after the East Japan Disaster. J Med Invest. 2013;60(1-2):61-65.

48. Brackbill RM, Hadler JL, DiGrande L, et al. Asthma and posttraumatic stress symptoms 5 to 6 years following exposure to the World Trade Center terrorist attack. JAMA. 2009;302(5):502-516.

49. Tomita K, Hasegawa Y, Watanabe M, Sano H, Hitsuda Y, Shimizu E. The Tottori-Ken Seibu earthquake and exacerbation of asthma in adults. J Med Invest. 2005;52(1-2):80-84.

50. Fukuhara A, Sato S, Uematsu M, et al. Impacts of the 3/11 disaster in Fukushima on asthma control. Am J Respir Crit Care Med. 2012; 186(12):1309-1310.

51. Kobayashi S, Hanagama M, Yamanda S, Yanai M. Home oxygen therapy during natural disasters: lessons from the great East Japan earthquake. Eur Respir J. 2012;39(4):1047-1048.

52. Kimmel PL. Chronic kidney disease and disasters: what may the societies do? Clin J Am Soc Nephrol. 2007;2(4):801-802.

53. Sever MS, Lameire N, Vanholder R. Renal disaster relief: from theory to practice. Nephrol Dial Transplant. 2009;24(6):1730-1735.

54. Vanholder RC, Van Biesen WA, Sever MS. Hurricane Katrina and chronic dialysis patients: better tidings than originally feared? Kidney Int. 2009;76(7):687-689.

55. Nangaku M, Akizawa T. Diary of a Japanese nephrologist during the present disaster. Kidney Int. 2011;79(10):1037-1039.

56. Fukagawa M, Kim JI, Fujii H. Another role for nephrologists in disaster medicine. Clin Exp Nephrol. 2013;17(2):153-154.

57. Haga N, Hata J, Yabe M, et al. The Great East Japan Earthquake affected the laboratory findings of hemodialysis patients in Fukushima. BMC Nephrol. 2013;14:239.

58. Ko JY, Strine TW, Allweiss P. Chronic conditions and household preparedness for public health emergencies: Behavioral Risk Factor Surveillance System, 2006-2010. Prehosp Disaster Med. 2014;29(1): 13-20.

59. Federal Emergency Management Agency [webpage on the Internet]. Preparing for disaster for people with disabilities and other special needs. Washington, DC: Federal Emergency Management Agency; 2009. Available from: http://www.fema.gov/media-library/assets/documents/897. Accessed August 1, 2014.

60. D’Arrigo T. Dodging disaster. Hurricane Katrina struck New Orleans like a battering ram, but Sid Seruntine was ready. Diabetes Forecast. 2006;59(2):53-55.

61. Renukuntla VS, Hassan K, Wheat S, Heptulla RA. Disaster preparedness in pediatric type 1 diabetes mellitus. Pediatrics. 2009;124(5): e973-e977.

62. Baggett J. Florida disasters and chronic disease conditions. Prev Chronic Dis. 2006;3(2):A66.

63. Tomio J, Sato H, Mizumura H. Interruption of medication among outpatients with chronic conditions after a flood. Prehosp Disaster Med. 2010;25(1):42-50. 
64. Potini VC, Weerasuriya DN, Lowery-North DW, Kellermann AL. Commercial products that convey personal health information in emergencies. Disaster Med Public Health Prep. 2011;5(4): 261-265.

65. Tanihara S, Tomio J, Kobayashi Y. Using health insurance claim information for evacuee medical support and reconstruction after the Great East Japan Earthquake. Disaster Med Public Health Prep. 2013;7(4): 403-407.

66. Centers for Disease Control and Prevention. Public Health Preparedness Capabilities: National Standards for State and Local Planning, March 2011. Atlanta, GA: Centers for Disease Control and Prevention; 2011 [updated July 22, 2011]. Available from: www.cdc.gov/phpr/capabilities. Accessed August 1, 2014.

67. Holt JB, Mokdad AH, Ford ES, Simoes EJ, Mensah GA, Bartoli WP. Use of BRFSS data and GIS technology for rapid public health response during natural disasters. Prev Chronic Dis. 2008;5(3):A97.

68. Jhung MA, Shehab N, Rohr-Allegrini C, et al. Chronic disease and disasters medication demands of Hurricane Katrina evacuees. Am J Prev Med. 2007;33(3):207-210.
69. Baker LR, Baker MD. Disaster preparedness among families of children with special health care needs. Disaster Med Public Health Prep. 2010;4(3):240-245.

70. Bethel JW, Foreman AN, Burke SC. Disaster preparedness among medically vulnerable populations. Am J Prev Med. 2011;40(2):139-143.

71. Eisenman DP, Wold C, Fielding J, et al. Differences in individual-level terrorism preparedness in Los Angeles County. Am J Prev Med. 2006; 30(1):1-6.

72. Eisenman DP, Zhou Q, Ong M, Asch S, Glik D, Long A. Variations in disaster preparedness by mental health, perceived general health, and disability status. Disaster Med Public Health Prep. 2009;3(1): 33-41.

73. Heslin KC, Gin JL, Afable MK, Ricci K, Dobalian A. Personal medication preparedness among veteran and nonveteran men and women in the California population. Prehosp Disaster Med. 2013;28(4): 359-366.

74. Tomio J, Sato H, Mizumura H. Disparity in disaster preparedness among rheumatoid arthritis patients with various general health, functional, and disability conditions. Environ Health Prev Med. 2012;17(4): 322-331.

\section{Publish your work in this journal}

Open Access Emergency Medicine is an international, peer-reviewed, open access journal publishing original research, reports, editorials, reviews and commentaries on all aspects of emergency medicine. The manuscript management system is completely online and includes a very quick and fair peer-review system, which is all easy to use.

\section{Dovepress}

Visit http://www.dovepress.com/testimonials.php to read real quotes from published authors. 